\title{
Palm Olein as Renewable Raw Materials for Industrial and Pharmaceutical Products Applications: Chemical Characterization and Physicochemical Properties Studies
}

\author{
Darfizzi Derawi, ${ }^{1}$ Bashar Mudhaffar Abdullah, ${ }^{1,2}$ Hasniza Zaman Huri, ${ }^{2,3}$ \\ Rahimi M. Yusop, ${ }^{1}$ Jumat Salimon, ${ }^{1}$ Nany Hairunisa, ${ }^{2}$ and Nadia Salih ${ }^{1}$ \\ ${ }^{1}$ School of Chemical Sciences and Food Technology, Faculty of Science and Technology, Universiti Kebangsaan Malaysia, \\ 43600 Bangi, Selangor Darul Ehsan, Malaysia \\ ${ }^{2}$ Clinical Investigation Centre, University Malaya Medical Centre, 13th Floor Main Tower, Lembah Pantai, \\ 59100 Kuala Lumpur, Malaysia \\ ${ }^{3}$ Department of Pharmacy, Faculty of Medicine, University of Malaya, 50603 Kuala Lumpur, Malaysia
}

Correspondence should be addressed to Darfizzi Derawi; darfizzi@ukm.my and Hasniza Zaman Huri; hasnizazh@um.edu.my

Received 2 February 2014; Revised 8 July 2014; Accepted 8 July 2014; Published 18 September 2014

Academic Editor: Luigi Nicolais

Copyright (C) 2014 Darfizzi Derawi et al. This is an open access article distributed under the Creative Commons Attribution License, which permits unrestricted use, distribution, and reproduction in any medium, provided the original work is properly cited.

\begin{abstract}
Palm olein $\left(\mathrm{PO}_{\mathrm{o}}\right)$ is widely produced as edible oil in tropical countries. $\mathrm{PO}_{\mathrm{o}}$ is considered as renewable raw material for the new industrial and pharmaceutical products synthesis based on its characterization. Palm olein was good on its viscosity index, oxidative stability, and flash and fire point. $\mathrm{PO}_{\mathrm{o}}$ contained unsaturated triacylglycerols (TAGs): POO (33.3\%); POP (29.6\%) which plays an important role in chemical modification process to produce new industrial products. The double bond was detected on ${ }^{1} \mathrm{H}$ NMR (5.3 ppm) and ${ }^{13} \mathrm{C}-\mathrm{NMR}(130 \mathrm{ppm})$ spectra. The chemical compositions of $\mathrm{PO}_{\mathrm{o}}$ were tested by using high performance liquid chromatography (HPLC) and gas chromatography (GC) techniques. This unsaturated oil is potentially to be used as renewable raw materials in chemical modification process to synthesise polyols, polyurethane, and biolubricant for industrial and pharmaceutical products application.
\end{abstract}

\section{Introduction}

Recently, researchers all over the world study about the new approaches in chemical synthesis technique to produce industrial and pharmaceutical products such as polymers, fuels, and lubricants. Conventionally, petro-based products are produced widely, but this leads to the decreasing of petroleum source; then the price becomes unstable. Moreover, some environmental issues also are claimed out. As a result, some of the environmentally friendly sources that can initiate green materials technology in chemical synthesis were found out. Commonly, these sources had been used traditionally as herbs or food usage for a long time. Because of the lack of scientific researches, the potential of these crops as natural friendly sources on developing the industrial products cannot be discovered [1].

Palm oil is from the fleshy endosperm of oil palm with scientific name being Elaeis guineensis [1]. Palm oil undergoes some refineries stages such as fractionation distillation, refining, bleaching, and deodorization to produce refined, bleached, and deodorized palm oil (RBDPO). A single fractionation converts palm oil to palm olein by $75-80 \%$ yield [2]. Palm olein $\left(\mathrm{PO}_{\mathrm{o}}\right)$ is the most valuable liquid fraction of palm oil (the largest renewable resources in Malaysia). It is used for frying and for salad oils [1].

It mainly consists of monounsaturated triacylglycerol (TAG), POP (42.8\%), and diunsaturated TAG, POO (35.7\%). The iodine value of $\mathrm{PO}_{\mathrm{o}}$ is about 51.0-61.0 [3]. $\mathrm{PO}_{\mathrm{o}}$ consists of oleic acid (42.7-43.9\%) and palmitic acid (39.5-40.8\%) [4]. Oleic acid was a monounsaturated fatty acid while palmitic acid was a saturated fatty acid attached to the TAG of $\mathrm{PO}_{\mathrm{o}}$. Oleic acid needed to improve the pour point and cloud point value of $\mathrm{PO}_{\mathrm{o}}$. While the palmitic acid needed to improve the oxidative and thermal stability. So, the combination of monounsaturated and saturated properties of $\mathrm{PO}_{\mathrm{o}}$ makes it preferable as raw materials usage in new industrial products 


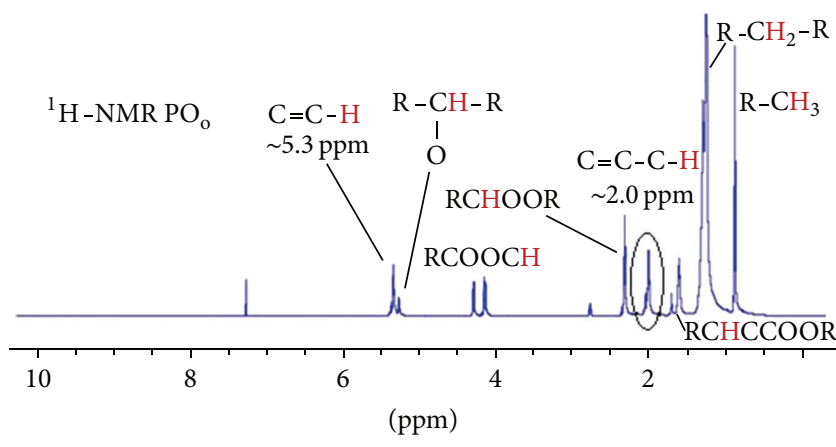

Figure 1: The ${ }^{1} \mathrm{H}$-NMR spectrum of $\mathrm{PO}_{\mathrm{o}}$.

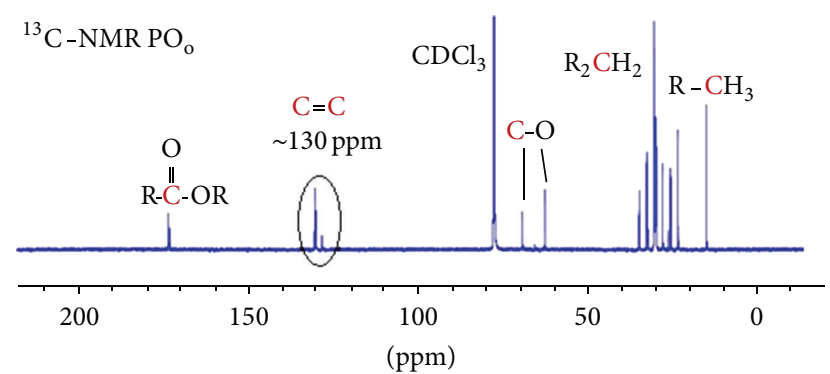

Figure 2: The ${ }^{13} \mathrm{C}-\mathrm{NMR}$ spectrum of $\mathrm{PO}_{\mathrm{o}}$.

research. In this paper, we report that the chemical characterization and physicochemical properties of $\mathrm{PO}_{\mathrm{o}}$ which potentially to be developed as raw materials in industrial products synthesis.

\section{Results and Discussion}

\subsection{Chemical Characterization}

2.1.1. Proton and Carbon Characterization. $\mathrm{PO}_{0}$ showed the presence of unsaturated bond based on the proton, ${ }^{1} \mathrm{H}$ NMR (Figure 1), and carbon, ${ }^{13} \mathrm{C}-\mathrm{NMR}$ (Figure 2), spectra at $5.3 \mathrm{ppm}$ and $130 \mathrm{ppm}$. Theoretically, the chemical shift of unsaturated bond can be detected on 4.5-6.5 ppm (proton) and $40-80 \mathrm{ppm}$ (carbon) [5]. This unsaturated carbon is favoured in order to perform further reaction in chemical modification process.

2.1.2. FFA Composition (GC Analysis). Based on the GC analysis done, there were three major FFAs of $\mathrm{PO}_{\mathrm{o}}$ (Table 1). These FFAs were oleic acid (47.7\%) followed by palmitic acid (36.3\%) and linoleic acid (10.4\%). The others were lauric acid $(0.2 \%)$, myristic acid $(0.8 \%)$, stearic acid (3.7\%), linolenic acid $(0.3 \%)$, and arachidic acid (0.1\%). Compared to the theory, palm olein contained lauric acid (0.1-0.2\%), myristic acid (0.9-1.0\%), palmitic acid (39.5-40.8\%), C16:1 $(<0.2 \%)$, stearic acid (3.9-4.4\%), oleic acid (42.7-43.9\%), linoleic acid (10.6$11.4 \%)$, linolenic acid $(<0.4 \%)$, and arachidic acid $(0.1-0.3 \%)$ [4].

The FFA compositions of $\mathrm{PO}_{\mathrm{o}}$ had been reported before [6]. It contained lauric acid (0.2\%), myristic acid (1.1\%), palmitic acid (35.7\%), stearic acid (3.5\%), oleic acid (45.4\%),
TABLE 1: The FFA compositions of $\mathrm{PO}_{0}$.

\begin{tabular}{lccc}
\hline Number & FFA type & $\begin{array}{c}\text { Retention time } \\
\text { (minutes) }\end{array}$ & $\begin{array}{c}\text { Relative area } \\
(\%)\end{array}$ \\
\hline 1 & Lauric acid & 10.829 & 0.2 \\
2 & Myristic acid & 14.689 & 0.8 \\
3 & Palmitic acid & 19.518 & 36.3 \\
4 & Palmitoleic acid & 20.187 & 0.2 \\
5 & Stearic acid & 24.085 & 3.7 \\
6 & Oleic acid & 24.895 & 47.7 \\
7 & N/A & 25.581 & 0.2 \\
8 & Linoleic acid & 25.986 & 10.4 \\
9 & N/A & 27.515 & 0.1 \\
10 & Linolenic acid & 27.773 & 0.3 \\
11 & Arachidic acid & 28.558 & 0.1 \\
\hline
\end{tabular}

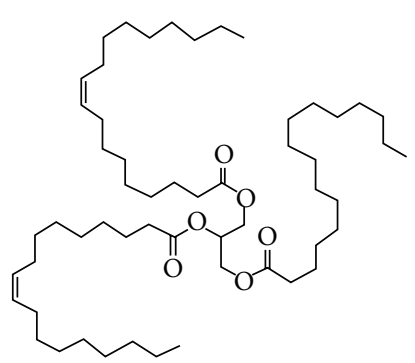

Figure 3: Major structure of TAG $\mathrm{PO}_{\mathrm{o}}$ (POO).

linoleic acid (13.1\%), and linolenic acid (0.3\%). The separation of GC peaks was based on the carbon number and boiling point of each compound. The greater the carbon number, the longer the retention time for the peak detected. The same happened to the FFA that had double bond on its structure because the double bond will increase the intermolecular force. By increasing the intermolecular force, the boiling point was increased and the retention time also increased.

2.1.3. Triacylglycerol Composition (HPLC Analysis). Based on the HPLC analysis done, there were two major triacylglycerols (TAGs) found which are POO (33.3\%) (Figure 3) and POP (29.6\%) (Table 2). This is because the major FFA of $\mathrm{PO}_{\mathrm{o}}$ was oleic acid followed by palmitic acid. The separation of HPLC peaks was based on the equivalent carbon number $(E C N)$ and the polarity of each TAG. Different ECN produced the different based line of the peak. The greater the ECN number, the shorter the retention time. But, for the same based line of TAGs, the less polar of TAG was firstly detected. The arrangement of TAGs was PLL (2.8\%), OOL (1.4\%), POL (12.4\%), PPL (7.3\%), OOO (3.6\%), POO (33.3\%), POP (29.6\%), SOO (2.6\%), and POS (3.8\%).

The theoretical TAG composition of palm oil itself mainly contained POP (27-31\%) and POO (20-26\%) (Gunstone, 2004). Because the palm oil had fractionised to produce $\mathrm{PO}_{\mathrm{o}}$, so that the TAG was higher contained of olein. Compared to the HPLC analysis of $\mathrm{PO}_{0}$ done before, there were OLL (0.7\%), OOL (2.6\%), POL (14.8\%), PPL (10.2\%), OOO (5.5\%), POO (30.6\%), POP (18.0\%), and SOO (3.3\%) [6]. 
TABle 2: The TAG compositions of $\mathrm{PO}_{\mathrm{o}}$.

\begin{tabular}{lcc}
\hline TAG type & $\begin{array}{c}\text { Equivalent carbon number } \\
(\mathrm{ECN})\end{array}$ & $\begin{array}{c}\text { Relative area } \\
(\%)\end{array}$ \\
\hline PLL & 44 & 2.8 \\
OOL & 46 & 1.4 \\
POL & 46 & 12.4 \\
PPL & 46 & 7.3 \\
OOO & 48 & 3.6 \\
POO & 48 & 33.3 \\
POP & 48 & 29.6 \\
SOO & 50 & 2.6 \\
POS & 50 & 3.8 \\
\hline
\end{tabular}

TABle 3: Physicochemical properties of $\mathrm{PO}_{\mathrm{o}}$.

\begin{tabular}{lcc}
\hline Physicochemical test & Unit & Value $_{(\text {exp. }}$ \\
\hline Iodine value & $\mathrm{mg} \mathrm{KOH} / \mathrm{g}$ oil & 61.7 \\
Acidity & $\%$ & 3.01 \\
Saponification value & $\mathrm{mg} \mathrm{KOH} / \mathrm{g}$ & 197.2 \\
Average molecular weight & $\mathrm{gmol}^{-1}$ & 854.3 \\
Unsaponifiable matter & $\%$ & 0.17 \\
Moisture content (Karl Fischer) & $\%$ & 0.22 \\
Cloud point & ${ }^{\circ} \mathrm{C}$ & $7( \pm 1)$ \\
Pour point & ${ }^{\circ} \mathrm{C}$ & $5( \pm 2)$ \\
Flash point & ${ }^{\circ} \mathrm{C}$ & $>320( \pm 5)$ \\
Fire point & ${ }^{\circ} \mathrm{C}$ & $>320( \pm 5)$ \\
Oxidative stability $(\mathrm{DSC})$ & ${ }^{\circ} \mathrm{C}$ & 179 \\
Kinematic viscosity $\left(40^{\circ} \mathrm{C}\right)$ & $\mathrm{cSt}$ & 45.9 \\
Kinematic viscosity $\left(100^{\circ} \mathrm{C}\right)$ & $\mathrm{cSt}$ & 9.4 \\
Viscosity index & $\mathrm{n} / \mathrm{a}$ & 195 \\
\hline
\end{tabular}

2.2. Physicochemical Properties. The physicochemical of $\mathrm{PO}_{\mathrm{o}}$ has been shown in Table 3. The iodine value of $\mathrm{PO}_{\mathrm{o}}$ was 61.7 and the acidity was $3.01 \%$. This acidity may happen during the storage and delivering time of the sample. The saponification value was $197.2 \mathrm{mg} \mathrm{KOH} / \mathrm{g}$ and its average molecular weight of $\mathrm{PO}_{\mathrm{o}}$ was $854.3 \mathrm{gmol}^{-1}$. $\mathrm{PO}_{\mathrm{o}}$ contains 0.17 of unsaponifiable matter. This commercial oil just contains $0.22 \%$ of water. The cloud point was $7^{\circ} \mathrm{C}\left( \pm 1^{\circ} \mathrm{C}\right)$ and pour point was $5^{\circ} \mathrm{C}\left( \pm 2^{\circ} \mathrm{C}\right)$. Both fire and flash point were over $320^{\circ} \mathrm{C}\left( \pm 5^{\circ} \mathrm{C}\right)$. The oxidative stability by DSC was $179^{\circ} \mathrm{C}$. $\mathrm{PO}_{\mathrm{o}}$ has kinematic viscosity about $45.9 \mathrm{cSt}\left(40^{\circ} \mathrm{C}\right)$ and $9.4 \mathrm{cSt}$ $\left(100^{\circ} \mathrm{C}\right)$ with viscosity index of 195 [7]. Theoretically, the iodine value was not less than 55 . Then, the cloud point was $7-10^{\circ} \mathrm{C}$. The saponification value was $194-202$ and the unsaponifiable matter was less than 1.4 [1].

\section{Experimental}

3.1. Materials. $\mathrm{PO}_{\mathrm{o}}$ (Seri Murni brand, FFM Marketing Sdn. Bhd.) was purchased directly from the market in Malaysia.

\subsection{Methods}

\subsubsection{Chemical Characterization Test}

(1) Nuclear Magnetic Resonance (NMR). Proton ( $\left.{ }^{1} \mathrm{H}-\mathrm{NMR}\right)$ and carbon $\left({ }^{13} \mathrm{C}-\mathrm{NMR}\right)$ spectroscopy analysis were performed by using Spectrometer FT-NMR $600 \mathrm{MHz}$ CryoProbe, Advance $111600 \mathrm{MHz}$ model. Sample preparation was done by using chloroform $\left(\mathrm{CDCl}_{3}\right)$ solvent [8].

(2) Gas Chromatography (GC). GC analysis was run by GC instrument, 17A Shimadzu model. Firstly, the free fatty acid (FFA) converted to the fatty acid methyl ester (FAME) [9]. Then, $1.0 \mu \mathrm{L}$ of FAME was injected into the injector port. The injection temperature was $250^{\circ} \mathrm{C}$ with the detector temperature being $280^{\circ} \mathrm{C}$. The capillary column used was nonpolar stationery phase (BPX70) with helium as mobile gas. The initial temperature was $120^{\circ} \mathrm{C}$ and final temperature was $250^{\circ} \mathrm{C}$ with temperature rate being $3^{\circ} \mathrm{C}$ per minute for 58 minutes of analysis.

(3) High Performance Liquid Chromatography (HPLC). The HPLC analysis was run by HPLC auto sampler instrument, Dionex Ultimate 3000 model with nonpolar column (C18, $150 \mathrm{~mm} \times 4.8 \mathrm{~mm} \times 3 \mu \mathrm{m})$. The mobile phase used was a mixture of acetone: acetonitrile $(60: 40 \mathrm{v} / \mathrm{v})$. About $20 \mu \mathrm{L}$ of $\mathrm{PO}_{\mathrm{o}}$ sample was used for the 30 minutes of analysis [10].

\subsubsection{Physicochemical Properties Test}

(1) Iodine Value. About $0.5 \mathrm{~g}$ of $\mathrm{PO}_{\mathrm{o}}$ was used to test its unsaturation compounds. The iodine value of oil sample was determined by Wijs method (British standard BS 684: Section $2.13: 1976$ ) [11]. It can be defined as a measure of the unsaturation of fatty acids and is expressed in terms of the number of centigrams of iodine absorbed per gram of sample (\% iodine absorbed).

(2) Acid Value. The acidity of $\mathrm{PO}_{0}$ was determined by AOCS 5a-40 (1989) [11]. The acid value is the number of milligrams of potassium hydroxide required to neutralize the free fatty acids in $1 \mathrm{~g}$ of sample. $5 \mathrm{~g}$ of $\mathrm{PO}_{\mathrm{o}}$ was weighted into an Erlenmeyer flask. Then, $50 \mathrm{~mL}$ of neutralized solvent was poured into the flask. The flask with the sample was heated about $40^{\circ} \mathrm{C}$. The sample, then, was titrated with the standard alkali to the first permanent pink colour for 30 seconds.

(3) Cloud Point. The cloud point is temperature at which, under certain test conditions (A.O.C.S. Cc 6-25), a cloud is induced in the sample caused by the first stage of crystallization [11]. About $45 \mathrm{~mL}$ of sample was poured into a $120 \mathrm{~mL}$ sample bottle (Beatson). Then, the sample bottle had its content cooled in the water bath and stirred to homogenize the temperature. The sample was stirred rapidly in a circular motion when it reached a temperature about $10^{\circ} \mathrm{C}$ above the cloud point. The cloud point was recorded when the thermometer immersed in the oil is no longer visible when viewed horizontally through the bottle and sample. 
(4) Moisture Content. The moisture content of $\mathrm{PO}_{\mathrm{o}}$ was tested by Karl Fischer method (A.O.C.S. Tb 2-64) [12]. This method is to determine the actual water content of oil by titration with Fischer reagent which reacts quantitatively with water.

(5) Saponification Value. About $2 \mathrm{~g}$ of $\mathrm{PO}_{\mathrm{o}}$ was used to test the saponification value (British standards BS 6842.6 : 1977) [13]. The saponification value can be defined as the number of milligrams of potassium hydroxide $(\mathrm{KOH})$ required to saponify $1 \mathrm{~g}$ of fat under the conditions specified. It is a measure of the average molecular weight of all the fatty acids present.

(6) Unsaponifiable Material. $10 \mathrm{~g}$ of $\mathrm{PO}_{\mathrm{o}}$ was used to test the unsaponifiable matter (A.O.C.S. Ca 6a-40) [14]. This method is to test the unsaponifiable matter including those substances frequently found dissolved in oils which cannot be saponified by the caustic alkalies but are soluble in the ordinary fat solvents including the higher aliphatic alcohols, sterols, pigments, and hydrocarbons.

(7) Oxidative Stability. Oxidative stability of $\mathrm{PO}_{\mathrm{o}}$ was tested by using Pressurized Differential Scanning Calorimeter (PDSC), Mettler Toledo DSC 822 model with StarE software. About $4 \mathrm{mg}$ of sample was weighed in an aluminium pan. Then, the aluminium pan was sealed with a pinhole lid and oxidized in the presence of air [15]. A $10^{\circ} \mathrm{C} \mathrm{min}{ }^{-1}$ heating rate $\left(25^{\circ} \mathrm{C}\right.$ to $300^{\circ} \mathrm{C}$ ) was used for the test. The oxidation onset $\left(\mathrm{OT},{ }^{\circ} \mathrm{C}\right)$ and signal maximum temperatures $\left(\mathrm{SMT},{ }^{\circ} \mathrm{C}\right)$ were calculated from a plot of heat flow $(\mathrm{W} / \mathrm{g})$ versus temperature.

(8) Pour Point. Pour point can be defined as the lowest temperature, expressed as a multiple of $3^{\circ} \mathrm{C}$ at which the oil is observed to flow when cooled and examined under prescribed conditions (ASTM D 97-66) [16]. About $10 \mathrm{~mL}$ of $\mathrm{PO}_{\mathrm{o}}$ was poured into a $\mathrm{U}$-tube and then covered with aluminium foil at the top of that tube. Then, the sample in the U-tube was placed overnight in the freezer $\left(-80^{\circ} \mathrm{C}\right)$. After a night, sample was taken out and the cover was removed. The tube was turned down while the temperature recorded when the sample had started to flow.

(9) Fire and Flash Point. The fire and flash point test as ASTM D 92-78 [12]. The test cup is filled to a specified level with the sample. The temperature of the sample is increased rapidly at first and then at a slow constant rate as the flash point is approached. At specified intervals a small test flame is passed across the cup. The lowest temperature at which application of the test flame causes the vapours above the surface of the liquid to ignite is taken as the flash point. To determine the fire point, the test is continued until the application of the test flame causes the oil to ignite and burn for at least 5 seconds.

(10) Kinematic Viscosity and Viscosity Index. The viscosity of $\mathrm{PO}_{\mathrm{O}}$ was tested by using the Anton Paar rheometer (Physica MCR 301 model). The kinematic viscosity was followed the ASTM D 445-79 [12]. The viscosity index (ASTM D2270) was calculated by using the kinematic viscosity at $40^{\circ} \mathrm{C}$ and $100^{\circ} \mathrm{C}$ [6].

\section{Conclusions}

Based on the physicochemical and unsaturated properties of palm olein, it has a potential to be utilized as renewable raw material in chemical synthesis process to produce bio-based industrial products.

\section{Conflict of Interests}

The authors declare that they have no competing interests.

\section{Acknowledgments}

The authors would like to thank Universiti Kebangsaan Malaysia for the financial and technical support through research Grant nos. DPP-2014-058 and GGPM-2014-033 and also would like to acknowledge the Ministry of Science, Technology and Innovation (Scifund:12-02-03-2097), and University of Malaya, Malaysia (RG428/12HTM) for the financial support.

\section{References}

[1] F. D. Gunsotne, The Chemistry of Oils and Fats, Sources, Composition, Properties and Uses, Blackwell, Oxford, UK, 2004.

[2] F. D. Gunstone and F. B. Padley, Lipid Technologies and Applications, Marcel Dekker, New York, NY, USA, 1997.

[3] R. D. O'Brien, Fats and Oils; Formulating and Processing for Applications, Technomic Publishing AG, Basel, Switzerland, 1998.

[4] F. D. Gunstone, J. L. Harwood, and F. B. Padley, The Lipid Handbook, Chapman \& Hall, London, UK, 2nd edition, 1994.

[5] D. L. Pavia, Introduction to Spectroscopy, Thomson Learning, Stamford, Conn, USA, 2001.

[6] M. R. Ramli, W. L. Siew, and K. Y. Cheah, "Properties of higholeic palm oils derived by fractional crystallization," Journal of Food Science, vol. 73, no. 3, pp. C140-C145, 2008.

[7] G. W. Stachowiak and A. W. Batchelor, Engineering Tribology, Elsevier, London, UK, 3rd edition, 2005.

[8] D. Derawi and J. Salimon, "Palm olein polyols production by batch and continuous hydrolisis," Sains Malaysiana, vol. 42, no. 8, pp. 1121-1129, 2013.

[9] J. Salimon, B. M. Abdullah, and N. Salih, "Selectively increasing of polyunsaturated (18:2) and monounsaturated (18:1) fatty acids in Jatropha curcas seed oil by crystallization using D-optimal design," Chemistry Central Journal, vol. 6, no. 1, article 65, 2012.

[10] J. Salimon, B. M. Abdullah, and N. Salih, "Hydrolysis optimization and characterization study of preparing fatty acids from Jatropha curcas seed oil," Chemistry Central Journal, vol. 5, no. 1, article 67, 2011.

[11] J. Salimon, M. Said, S. Ramli, and M. A. S. Mat Lazim, Oils and Fats Analysis, Penerbit UKM, Bangi, Malaysia, 2006.

[12] Emery, Emery Analytical Testing Procedures, Emery Industries, Cincinnati, Ohio, USA, 1983.

[13] J. Salimon, B. M. Abdullah, and N. Salih, "Saponification of jatropha curcas seed oil: optimization by D-optimal design," International Journal of Chemical Engineering, vol. 2012, Article ID 574780, 6 pages, 2012. 
[14] B. M. Abdullah and J. Salimon, "Physicochemical characteristics of Malaysian rubber (Hevea Brasiliensis) seed oil," European Journal of Scientific Research, vol. 31, no. 3, pp. 437-445, 2009.

[15] N. Salih, J. Salimon, E. Yousif, and B. M. Abdullah, "Biolubricant basestocks from chemically modified plant oils: ricinoleic acid based-tetraesters," Chemistry Central Journal, vol. 7, no. 1, article 128, 2013.

[16] J. Salimon, N. Salih, and B. M. Abdullah, "Diesters biolubricant base oil: synthesis, optimization, characterization, and physicochemical characteristics," International Journal of Chemical Engineering, vol. 2012, Article ID 896598, 10 pages, 2012. 

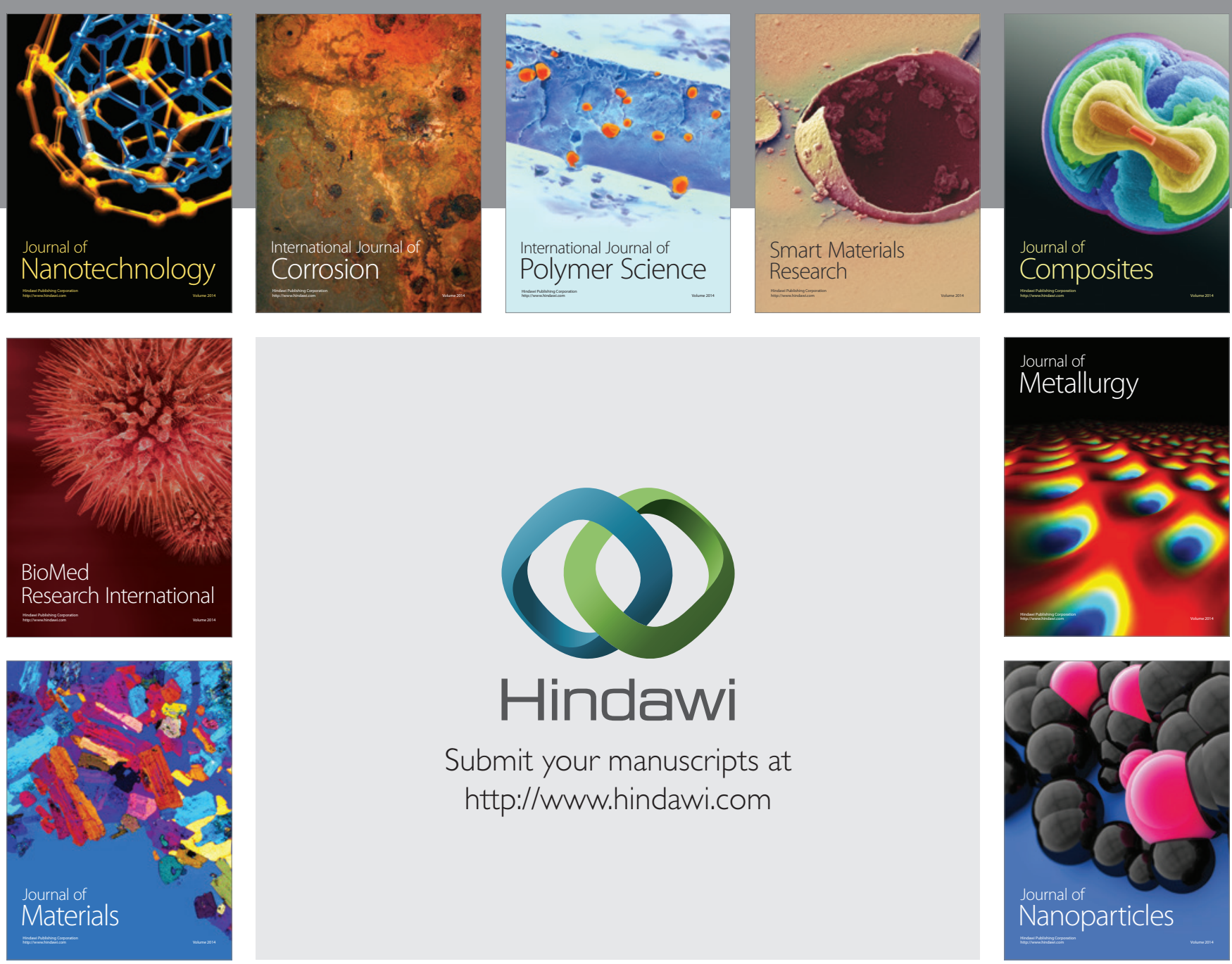

Submit your manuscripts at http://www.hindawi.com
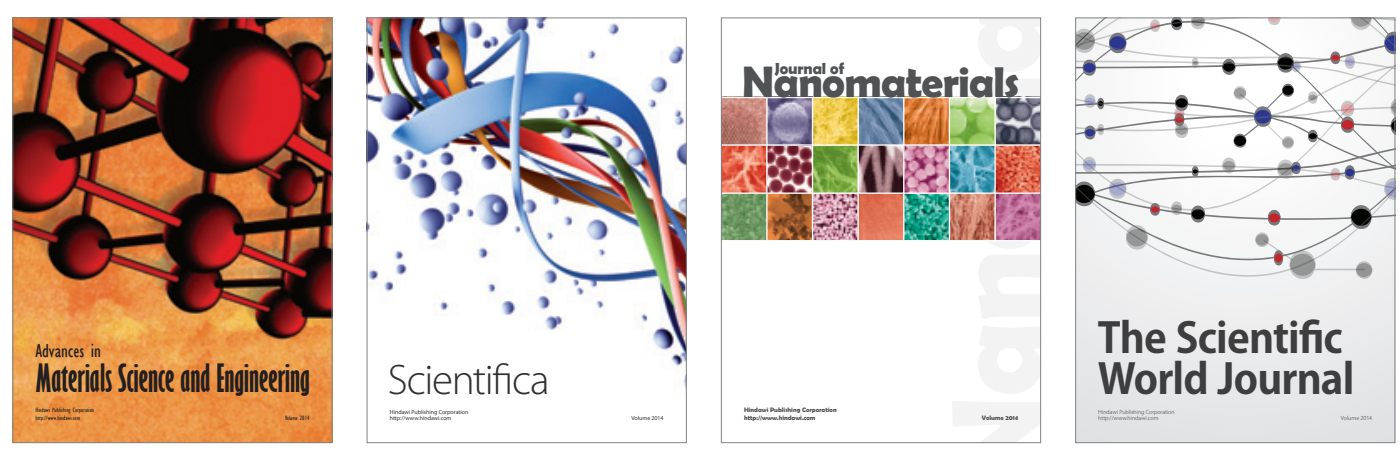

\section{The Scientific World Journal}
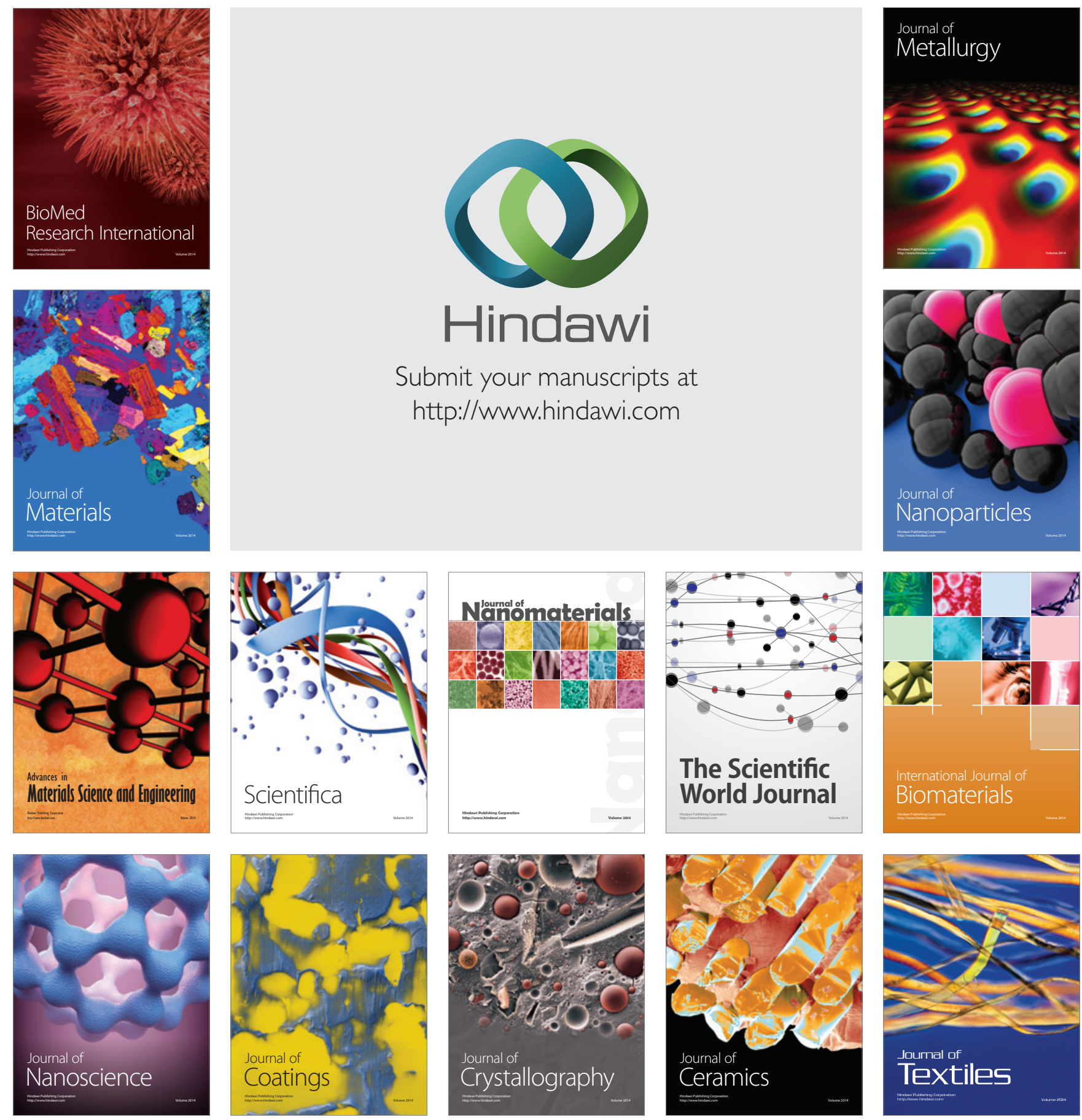